\title{
Travelers' compliance with social routing advice: evidence from SP and RP experiments
}

\author{
Mariska van Essen $^{1}$ (D) $\cdot$ Tom Thomas $^{1} \cdot$ Eric van Berkum $^{1} \cdot$ Caspar Chorus $^{2}$
}

Published online: 22 October 2018

(c) The Author(s) 2018

\begin{abstract}
This study examines to what extent travel information can be used to direct travelers to system-optimal routes that may be sub-optimal for them personally, but contribute to network efficiency. This is done by empirically examining determinants of travelers' compliance with social routing advice. To that end, we conducted both a stated choice experiment and a revealed choice experiment (which also collected stated intentions and motivations for revealed behavior). Results from the stated choice experiment indicate a significant difference in compliance behavior across different information frames, societal goals, sizes of travel time sacrifices and personality. These findings are less evident from results based on analysis of revealed choices; i.e., the main motivation for revealed compliance seems to be an intrinsic motivation to contribute to improved throughput, while the main motivation for non-compliance relates to perceived traffic conditions. Moreover, the size of the travel time sacrifice seems not that important as expected. Nonetheless, comparing stated intentions with real-world behavior suggests that a relation between intention and compliance frequency does exist.
\end{abstract}

Keywords Travel information · Road network efficiency $\cdot$ Route choice $\cdot$ Stated- and revealed preference $\cdot$ Social routing $\cdot$ Experience-based sampling

Mariska van Essen

m.a.vanessen@utwente.nl

Tom Thomas

t.thomas@utwente.nl

Eric van Berkum

e.c.vanberkum@utwente.nl

Caspar Chorus

c.g.chorus@tudelft.nl

1 Centre for Transport Studies, Faculty of Engineering Technology, University of Twente, Drienerlolaan 5, 7522 NB Enschede, The Netherlands

2 Transport and Logistics Group, Faculty of Technology, Policy and Management, Delft University of Technology, Jaffalaan 5, 2628 BX Delft, The Netherlands 


\section{Introduction}

Travel information is expected by many scholars and practitioners alike to be successful in improving road network efficiency by directing the network state from a user equilibrium towards a system optimum. Yet, conventional (personalized) travel information aims at the individual's benefit, stimulating travelers' personal optimization of their own route choices (so-called selfish routing behavior); this may lead to an inefficient user equilibrium (e.g., Ben-Akiva et al. 1991). Note that the road network might even more than ever before be approaching a perfect user equilibrium due to the rapid increase of real-time communitybased routing applications on smartphones (such as Waze 2018), as properly pinpointed by Klein et al. (2018). As selfish routing tends to result in severe congestion at certain locations in the road network and slow down overall traffic movement, traffic authorities tend to pursue system (or social) optimal network conditions in which the total travel time-and therewith congestion-within the network is minimized. Examples on network efficiency, such as Pigou's example (Pigou, as cited by Roughgarden 2006) and Braess's Paradox (Braess et al. 2005), have shown that in order to achieve system optimal network conditions, some travelers need to act socially and choose route alternatives possibly at their own expense (i.e., they might need to take a detour), referred to as social routing behavior. See Levy et al. (2017) and Klein et al. (2018) for two recent theoretical and simulationbased expositions of how different behaviors at the micro-level may lead to system-optimal outcomes.

Several steering approaches in order to direct travelers towards these social routes exist; examples are road pricing and the use of personalized incentives (e.g., discounts or rewards). These conventional steering approaches have shown to be successful in changing behavior (e.g., Anas and Lindsey 2011; Ettema et al. 2010), although their social desirability is questioned (e.g., Te Brömmelstroet 2014; Verhoef et al. 1997). The provision of travel information and social routing advice is another approach that is receiving increasingly attention recently (e.g., Jahn Möhring et al. 2005; Van den Bosch et al. 2011; Xu and Gonzalez 2017; Çolak et al. 2016). However, those studies mainly build upon theoretical assumptions rather than empirical findings. As such, a crucial and unanswered empirical research question in this regard is whether travelers comply with received route advice- or can be motivated to-when the advised route implies a personal travel time sacrifice for the benefit of others (i.e., the system as a whole). To that end, we empirically assess travelers' compliance with social routing advice. Note that we define compliance as a route choice in accordance with received route advice.

We collect empirical data on social route choices in response to social travel information strategies using both a stated choice experiment (SP) and a revealed choice experiment (RP). In order to enrich the information obtained from revealed choices, we combine the RP experiment with the experience-based sampling (ES) method; asking a subject about its behavior and motivations in a certain situation directly after that particular situation has revealed itself. This method is not often used in travel behavior research yet, although it is highly useful in assessing route choice behavior in response to social routing advice in realworld daily-life context. A review of the applied methods and their limitations is provided in "Literature review" section. Moreover, we develop and test several information framing strategies that aim to stimulate social route choice behavior. In line with a recent literature review on the role of social choice behavior, bounded rationality and travel information in improving road network efficiency (Van Essen et al. 2016), we take into account the degree of rationality in travelers' decision strategy and their intrinsic inclination towards choosing 
the social route. In addition to this focus on the framing of travel information and personal characteristics, we pay attention to both the size of the travel time sacrifice and the societal goal underlying the information; i.e. we go beyond existing research by not only looking into information messages pursuing a system optimum, but also into messages aiming at other societal benefits, such as traffic safety and environmental sustainability.

In sum, our study contributes to the existing literature by (1) the development of several information framing strategies taking into account personal characteristics, (2) the extended focus on the size of the travel time sacrifice and the societal goal underlying the information, and (3) the collection and use of empirical data on social route choices using both SP and RP in combination with ES. The remainder of this paper is structured as follows. "Literature review" section provides the research background, whereas "Methodology" section introduces the developed information strategies and describes the experimental set-ups and methodologies. Subsequently, "Results" section shows results and findings from the data analysis. Finally, this paper discusses the results in "Discussion" section and presents key conclusions in "Conclusion" section.

\section{Literature review}

Neoclassical choice theories largely build upon two behavioral assumptions, i.e., individuals are rational in how they choose and selfish in what they choose. This concept is widely criticized by behavioral economists who build upon psychology, social sciences and economics in order to explain deviations from this rational selfish choice behavior. Main line of criticism is that individuals have cognitive limitations, make errors, have biases or emotions influencing their decision making (e.g., Simon 1955; Tversky and Kahneman 1991; Zajonc 1980), i.e., they are boundedly rational. Moreover, individuals can choose to simplify their decision strategy and seek a satisfactory alternative rather than the optimal alternative, often called satisficing (e.g., Simon 1955), or make their decisions in a habitual way and just use the alternative that provided the most positive experience in the past (e.g., Verplanken et al. 1997). One potential explanation for such behavior is that individuals tend to minimize their (cognitive) efforts at the cost of the accuracy of their choice outcome according to some sort of effort-accuracy trade-off framework (Johnson and Payne 1985). In line with this, several studies found that travelers choose a short travel time alternative, although not necessarily the shortest travel time alternative (e.g., Ciscal-Terry et al. 2016; Vreeswijk et al. 2015; Zhu and Levinson 2010). These findings indicate that individuals do not necessarily want to use the route alternatives that benefit them the most, are not able to correctly identify these or are not particularly interested in this. Building upon principles of bounded rationality, Avineri (2009a) provides travel-related examples that illustrate how small adaptations to the presentation of travel information could direct travelers to social choice options without them even realizing it. Moreover, many studies found evidence that individuals do not exclusively behave in selfish ways, but that they do care about others' welfare as well (e.g., Georgescu-Roegen 1954; Ostrom and Walker 2003; Poteete et al. 2010; Sen 1977). A traffic-related example of this behavior is that car drivers often give right of way to others at intersections, merges, or lane changes, accepting a (very) short delay to avoid delay for others (although often imposed by regulations). Although studies within various fields continued this line of research, researchers within the field of transportation started to consider social choice behavior only more recently, and mostly related to sustainable transportation (e.g., Nilsson and Küller 2000; Van Vugt et al. 1996). 
A few recent studies examine the impacts of social choice behavior on road network efficiency and found that when all travelers start to value social outcomes only slightly, up to $60 \%$ of potential travel time savings could be attained (Avineri 2009b; Levy et al. 2017; Çolak et al. 2016), although lower results are obtained when only a minority of travelers choose their routes (fully) socially; i.e., about 7\% (Van den Bosch et al. 2011). Moreover, Djavadian et al. (2014) provide some initial evidence that travelers are willing to comply with social routing advice, especially when incentives are provided. Besides the study by Djavadian et al. (2014), little empirical evidence and knowledge of social choice behavior related to specifically route choices exist. Hence, further research on this topic is necessary.

In order to engage in certain behavior-such as making social route choices-individuals have to evaluate that behavior positively. It has been suggested that one's attitude towards social choice behavior is related to the individual's social value orientation, which represents his or her preference for certain outcomes for him- or herself as well as for others (Knight and Dubro 1984; Platow 1993). Multiple orientations have been identified although most studies use a three-category typology focusing on cooperative, individualistic and competitive orientations (Platow 1993). Cooperatives tend to maximize outcomes for both themselves and others, often combined with minimization of the relative differences between those outcomes (i.e., equity/equality); individualists tend to maximize their own outcome, regardless of others' outcome; and competitors tend to maximize the difference between their own outcomes and those of others (e.g., Van Lange et al. 1997). However, these personality traits do not tell the entire story: in order to make social choices, individuals need not only to be 'cooperatively oriented', they need to believe that others make social choices as well (Pruitt and Kimmel 1977). That is, social choice behavior depends on the individual's belief of the extent to which the collective goal can be achieved (often referred to as 'trust', e.g., Van Lange et al. 1998; Yamagishi 1988). Moreover, the opinion of peers and society, as well as the feeling of moral obligations, play an important role (e.g., Ajzen 1991; Schwartz 1977). These moral obligations stem from individuals' awareness of the consequences of certain behavior (e.g. traffic congestion or environmental damage caused by car and road use) and the extent to which they feel responsible for these consequences (Schwartz 1977).

Findings and examples on non-selfish non-rational choice behavior lead to increased expectations that travelers might comply with travel information and routing advice that directs them towards a particular route alternative, not for their own sake, but to benefit the road network as a whole. Note that we do not regard bounded rationality as a prerequisite for social choice behavior. We only want to point out that its existence provides the opportunity to direct travelers towards social routes, especially when they are individually oriented, and that we might want to build upon this.

Several valid methods exist in order to assess travelers' compliance; i.e., stated choice experiments, laboratory experiments (including gamified experiments and experimental economics) or field experiments. Stated choice experiments and laboratory experiments are flexible and low-cost, attribute values can be easily controlled and behavioral responses can be easily observed (Kroes and Sheldon 1988; Verhoef and Franses 2003). However, it is debated how well findings from such studies can be extrapolated to the real world (Kroes and Sheldon 1988), especially when social choices are involved (Levitt and List 2007). Field experiments tend to have higher external validity, although they often suffer from smaller sample sizes-resulting in lower statistical power-and attribute values which cannot be properly controlled for, potentially even prohibiting statistical inference due to e.g., serial correlation. Because field experiments take place in a dynamic context in which behavior can change from day-to-day, qualitative data about motivations for certain 
choice behavior would be quite useful. To that end, researchers within the field of travel behavior collect travel diaries or have an observer present during the experiment (e.g., Hoogendoorn-Lanser et al. 2015; Tawfik and Rakha 2012). Another method, that is not often applied within this field of research, is the experience-based sampling method (Hektner et al. 2007); participants are asked about their behavior and motivations in a certain situation, directly after this situation revealed itself in daily-life. As such, the behavior of participants is not influenced by the presence of an observer, while more accurate data can be obtained compared to the use of diaries (i.e., answers are less dependent upon memory). In order to exploit the strengths and mitigate the weaknesses of each approach, we conduct both a stated choice experiment and revealed choice experiment in combination with experience-based sampling; and we compare their results.

\section{Methodology}

\section{Design of system-optimal information strategies}

Four system-optimal information strategies have been developed; these strategies aim to influence individuals' route choice behavior without restricting their freedom of choice, each with the objective to improve network efficiency. Strategies range from low information content (i.e., providing almost no contextual information) to high information content (i.e., providing detailed information on context as well as the importance and consequences of certain choices). Moreover, some strategies capitalize on travelers' bounded rationality, whereas others focus on influencing or reinforcing their attitude towards the social route alternative. Table 1 provides an overview of this classification. Each strategy combines several principles that are, according to literature, potentially successful in changing (travel) behavior. This is done in such a manner that the strategies are distinct from each other, while remaining realistic, credible and practical (this is the reason why some cells in Table 1 are empty).

Now, a short description of each strategy will be provided. The fully detailed operationalization of each strategy will follow in "Operationalization of information strategies" section.

- Strategy 1 'Recommendation': This strategy provides plain advice on the route alternative that the specific individual should choose to the desire of the traffic man-

Table 1 Overview of strategy classification

\begin{tabular}{llll}
\hline & $\begin{array}{l}\text { Low information } \\
\text { content }\end{array}$ & $\begin{array}{l}\text { Moderate information } \\
\text { content }\end{array}$ & $\begin{array}{l}\text { High information } \\
\text { content }\end{array}$ \\
\hline $\begin{array}{c}\text { Capitalize on existing bounded } \\
\text { rationality }\end{array}$ & $\begin{array}{l}\text { Strategy 1 'Recom- } \\
\text { mendation' }\end{array}$ & Strategy 2 'Nudge' & - \\
$\begin{array}{c}\text { Focus on influencing attitude } \\
\text { towards behavioral change }\end{array}$ & - & $\begin{array}{c}\text { Strategy 3 'Social } \\
\text { Reinforcement' }\end{array}$ & Strategy 4 'Educate' \\
\hline
\end{tabular}


ager or road authority without any contextual information. Thereby, this strategy capitalizes on individuals' potential perception errors (Carrion 2013) or disinterest in choosing the shortest travel time alternative. Moreover, it reduces individuals' cognitive effort as it allows them to simply follow the provided recommendation (inspired by the effort-accuracy trade-off framework by (Johnson and Payne 1985).

- StRategy 2 'Nudge': This strategy presents information about the choice situation, and each choice option, in such a manner that individuals are somewhat directed towards the desired choice option without realizing it. The social route alternative is both presented first and emphasized as such, creating awareness of its existence. This is in line with the theory of default settings (e.g. Pichert and Katsikopolous 2007; Sunstein and Thaler 2003). Additionally, positive aspects of the social alternative, as well as negative aspects of the non-social alternatives are highlighted to make these salient (Avineri 2009a) and anticipate on potential loss aversion among travelers (Kahneman and Tversky 1979). Positive aspects are also emphasized in the label of the social route.

- StRAtegy 3 'Social Reinforcement': This strategy provides objective information about the choice situation and each choice option. Additionally, it provides information on the choices of others by showing the (in our experiment hypothetical) percentage of travelers that choose the social routing option (inspired by Araghi, Kroesen, Molin, and Van Wee (2014) who applied this principle in the context of carbon footprint offsetting). As a result, this strategy creates awareness about existing social norms regarding certain travel behavior and it reinforces trust or belief in a successful collective outcome or achievement (i.e., system optimum). Moreover, it puts their sacrifices (e.g., travel time, cost and effort) into perspective as they will know they are not the only ones making these sacrifices. Consequently, both an individual's normative belief and his or her attitude towards the desired social choice are potentially influenced.

- Strategy 4 'Educate': This strategy explains the context and importance of the individual's choice behavior for the desired collective outcome of achieving a system optimum. Moreover, it informs the traveler about each route alternative providing objective information on their characteristics. Finally, it instructs the traveler about the desired behavior by recommending the social alternative. As a result, this strategy creates consciousness about the context in which route choices take place and raises awareness of the consequences of individual's own behavior regarding the desired collective outcome.

\section{Stated choice experiment (SP): questionnaire}

\section{Participants}

211 respondents were recruited based on voluntary participation and self-assessment of eligibility; they were asked to only complete the questionnaire if they use a car for their commute at least every now and then. Links to the questionnaire were published on the employee portal of the University of Twente (Enschede, The Netherlands) and through social media (Facebook and Twitter). The survey was online from May to August, 2016. Respondents who completed the questionnaire could participate in a prize draw in which they could win a voucher — three vouchers were available — at the worth of $€ 50$, — which could be used at a well-known online shopping platform. 


\section{Materials}

The online questionnaire consisted of four parts; the first part collected stated choices through hypothetical situations, the second part assessed respondents' decision-making styles in line with dual-process theories developed within the field of cognitive psychology (e.g., Stanovich and West 2000), the third part assessed respondents' social value orientation and the final part of the questionnaire collected information about respondents' actual mobility pattern, both in general and related to their commute trip. Moreover, demographic information (i.e., age, gender, and education) was obtained. Validated questionnaires from the field of social psychology are used to assess respondents' decision-making styles and social value orientation.

A decision style which encompasses processes that are 'automatic, largely unconscious, and relatively undemanding of computation capacity' (Stanovich and West 2000, p. 658) is often associated with habitual behavior (e.g., Jakobssen 2003; Verplanken et al. 1997). We measure a habit-driven decision style by means of the decisional involvement scale that was developed by Verplanken et al. (1994) to examine habit in mode choice for shopping trips. This measure consists of eight statements using 5-point Likert-scales (Cronbach's $\alpha=.82$ ). A high score on the aggregate decisional involvement scale suggests that travelers made their route choices deliberately; no habit is involved. As decisional involvement is known to be highly dependent on the context, statements were presented with the stem 'When I commute by car...' and words related to mode choice were replaced with words related to route choice.

A decision style which 'encompasses the processes of analytic intelligence' (Stanovich and West 2000, p. 658) is often associated with maximizing behavior, as opposed to satisficing behavior. We measure maximizing versus satisficing decision-making by the context-free maximizing tendency scale that was developed by Lai (2010). This measure consists of five statements using a 5-point Likert-scale (Cronbach's $\alpha=.69$ ). A high score on this scale implies that the respondent has an intrinsic tendency to maximize, while a low score is associated with the intrinsic tendency to satisfice and choose the option that is 'good' enough.

We measure social value orientation using the canonical SVO-slider measure developed by Murphy et al. (2011). This measure provides respondents with six carefully designed choice situations in which they have to allocate a hypothetical money-budget to themselves and someone else. Importantly, the 'other person' is hypothetical and anonymous, and there is no follow-up in terms of the other person accepting or rejecting the offer (as in the ultimatum game). This SVO-measure has been found to be more reliable than previously used SVO constructs, such as the Ring Measure (Liebrand 1984) and the Triple-Dominance Measure (Van Lange et al. 1997), and is compatible with a route choice context, in the sense that road users are anonymous and in the sense that reciprocity does not play a role.

\section{Procedure}

In collecting stated choices, respondents were asked to picture a hypothetical commute trip. They were provided with travel information with respect to this commute trip according to one of the information strategies from "Methodology" section (i.e., there were four versions of the questionnaire-each containing only one of four information 
strategies - and each respondent received only one version of the questionnaire, which was randomly assigned). Respondents were told that the information message was received on their smartphone and was sent by their local road authority. They were asked to choose between two route alternatives: their (hypothetical) usual route that takes $28 \mathrm{~min}$ and some 'similar route' with a slightly higher travel time that contributes to a certain societal goal. The assumed timing of the information message is at trip departure.

\section{Design}

For the stated choice, a $2 \times 3$ full factorial design was used that considers travel time sacrifices imposed on the respondent (i.e., small versus large) and societal goals (i.e., congestion alleviation, traffic safety and environmental sustainability) that are aimed for by the information message; hence, respondents generally made six choices. Note that only three choices were made when the recommend-strategy was applied; this strategy did not provide travel time information and as such the travel time sacrifice did not vary. Travel time sacrifices of $3 \mathrm{~min}$ and $7 \mathrm{~min}$ are applied. These sacrifices originate from findings of a field study by Zhu and Levinson (2010) who found that many travelers who did not use their shortest travel time alternative, used alternatives that were less than 5 min longer than this shortest travel time alternative. The reason for distinguishing between different societal goals is that it allows us to study whether travelers' inclination to comply with the social routing advice depends on the goal which the government aims to achieve with the advice.

\section{Revealed choice experiment (RP): field experiment}

\section{Participants}

28 participants were voluntarily recruited among employees of companies located at the Business and Science Park Twente and the neighboring University of Twente in Enschede, The Netherlands. To that end, an advertisement was published on the employee portal of the University of Twente and an email was sent to the secretaries of companies and faculties. Employees were only eligible for participation if they made at least 3 commute trips per week by car during morning peak hour. It was ensured that their usual route to work passed certain predefined locations covering the main inbound routes to the destination area, guaranteeing the existence of an acceptable and realistic detour for their commute trip. The experiment took place during 5 consecutive weeks (January 16th until 17th February 2017).

Participants who completed the experiment could participate in a prize draw in which they could win an Ipad or a voucher - three vouchers were available - at the worth of $€ 50$,and $€ 20,-$, which could be used at a well-known online shopping platform.

\section{Materials}

Data was collected using the smartphone application 'SMART Mobility' (SMART in Twente 2016). This application automatically collects trip-data, i.e., origin, destination, departure time, arrival time, route and mode (-chain) for each trip. Further, the app can send messages to specific users and it can send specific questions to certain users which are triggered by the occurrence of a certain event or activity, according to the principle of Experience-based Sampling (Hektner et al. 2007). Moreover, participants filled out a 
short questionnaire in order to assess to what extent certain personality traits influenced their actual behavior. The exact same questionnaires and scales applied in the stated choice experiment were included in order to assess participants' decision styles and attitudes towards social behavior as well as the extent to which their route choices are deliberate or habit-driven.

\section{Procedure}

Participants installed the application 'SMART Mobility' on their personal smartphone. On working days, this application sends tailor-made information messages containing route advice for the morning commute to its users. The timing of the information message is set to 15 min before the user's average commute departure time to ensure that users receive the message before they depart. Participants were randomly assigned to one of two information strategies; i.e., the 'Recommend'-strategy or the 'Educate'-strategy. For two days every working week the social route was advised to each participant, while on the remaining days of the working week their usual route was advised. This is to avoid that participants feel that they themselves have to sacrifice all the time, while never reaping the benefits, and therefore might stop complying with the advice or do not comply at all. Note that the behavior of drivers who do not participate in the experiment does not change. Hence, actual benefits will not be experienced by participants. However, as demonstrated by Çolak et al. (2016), travel time benefits will be marginal (ranging from 1 to $3 \mathrm{~min}$ ) and might be imperceptible for the majority of travellers due to the natural variability in travel time caused by events, weather conditions and traffic lights. After a commute trip was made, app-users automatically received two questions about the main reason for choosing a particular route and the role that the information message played in that decision using experience-based sampling. Finally, actual travel times on both the usual and social routes were collected from Google Maps at a 5-min interval in order to monitor the road network and quantify the actual travel time sacrifices that have been made by the participants.

\section{Design}

Due to small sample size, only two out of four information strategies were applied; i.e., the 'Recommend'-strategy and the 'Educate'-strategy. These strategies were most distinctly classified regarding information content and focus. Moreover, only the commonly used goal to alleviate congestion was implemented. In order to enable within-subject comparison between stated choice and revealed choice, participants answered a question on their intended behavior at least 1 month before the start of the experiment; i.e., a choice situation, tailored to the participants' choice context as would be experienced during the field experiment, was provided. This 1 month time period was applied in order to limit the influence of the stated intention on participants' subsequent revealed behavior during the experiment.

\section{Datasets}

From this field experiment, we obtained two datasets; Stated Intention (SI) and Revealed Preference (RP). The SI-dataset contains the intended behavior before the start of the experiment provided by 22 participants. Note that these stated intentions are actually stated preferences; we use the term intentions in order to make a clear distinction between this 
dataset and the SP-dataset obtained from the questionnaire in "Stated choice experiment (SP) - questionnaire" section. The RP-dataset contains the actual behavior of 28 participants (including the 22 participants from the SI-dataset). We obtained 269 route choice observations in which the information message was read before reaching the passage point where the decision whether or not to comply should be made. In 116 of these 269 observations (43\%) the social route was advised. Since 3 participants either did not read the information message or did not undertake a commute trip on days that the social route was advised, the number of participants reduces to 25 for analyses that only consider these specific days.

\section{Operationalization of information strategies}

Table 2 provides an overview of our operationalization of each information strategy. In the SP-experiment, each message was embedded in a picture of a smartphone screen in order to increase realism.

\section{Outline of empirical analysis}

Our analysis consists of four parts. First, we provide compliance rates for each dataset to gain some initial insights and understanding. Note that compliance is measured as the event where the respondent or participant chooses the social route in line with received advice. As such, compliance might occur for some other reason than the received advice as well (we elaborate further on this in section "Analysis of motivations"). Subsequently, we compare findings between the SP, SI and RP datasets. Wardman (1988) identified two approaches to test the external validity of stated preferences that are mainly used in transportation contexts. The first approach is to compare stated intentions regarding a certain event with the actual behavior after the event has occurred; these are so-called 'before and after' studies. A second approach is the comparison of travel behavior models based on stated preferences and revealed preferences. We apply both approaches. For the first approach, SI and RP choices are compared in a descriptive way. For the second approach, choices made in SP and RP are analyzed by means of estimating discrete choice models on information compliance. Finally, we conduct qualitative analyses of motivations to comply with the received route advice to obtain insights into the reasons behind observed behavior. We use a 5\% significance level for all statistical tests.

\section{Model specification}

We estimated Mixed Logit models accounting for panel effects, taking into account that respondents and participants (in both experiments) made multiple choices and hence might carry some of their preferences across choice tasks.

Three models were estimated; one model based on the SP-dataset, one model based on the RP-dataset and one joint SP/RP-model based on both datasets. In the joint SP/RP-model both datasets are combined by scaling the utilities in one dataset in order to allow for differences in error term variance across datasets. We included three attributes in each model, i.e., the information strategy that was provided (4 levels in SP: Recommendation, Nudge, Social reinforcement, Education-2 levels in RP: Recommendation, Education), the societal goal that was pursued by the information content (3 levels in SP: alleviate congestion, 
Table 2 Overview of operationalization of information strategies




Table 2 (continued)

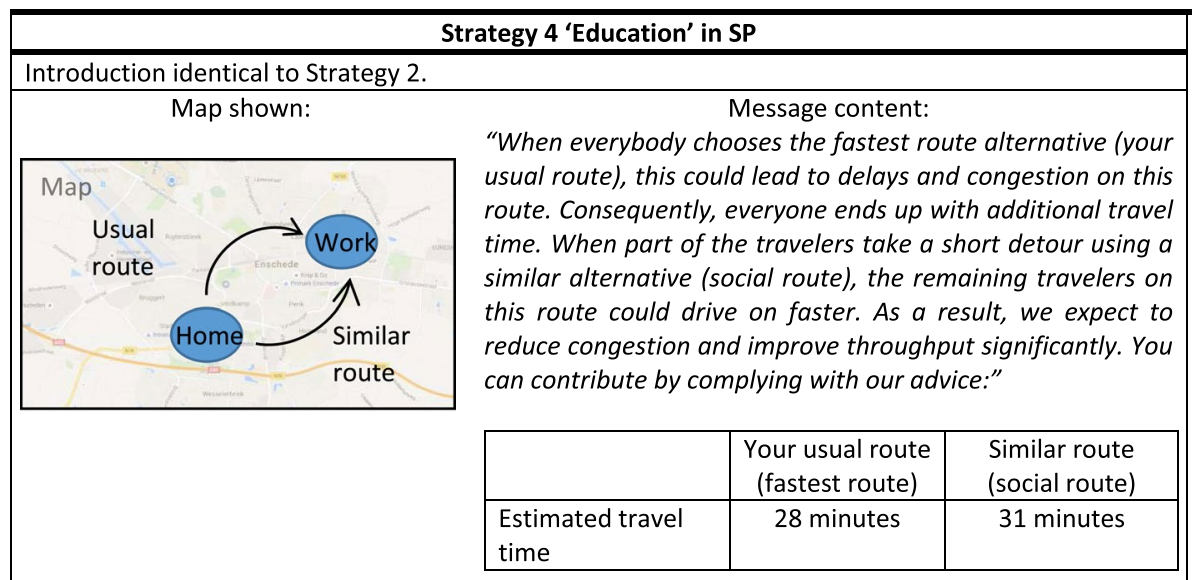

"We advise you to take the similar route today. This is the social alternative."

\begin{tabular}{|c|c|c|c|}
\hline \multicolumn{4}{|c|}{ Strategy 4 'Education' in SI and RP } \\
\hline \multicolumn{4}{|l|}{ No introduction } \\
\hline $\begin{array}{l}\text { Map shown (Tailor-made map using } \\
\text { 'Route } 1 \text { ' and 'Route } 2 \text { '): }\end{array}$ & \multicolumn{3}{|c|}{ Message content: } \\
\hline Kerspel Goor & \multicolumn{3}{|c|}{$\begin{array}{l}\text { "When everybody chooses the fastest route alternative (your } \\
\text { usual route), this could lead to delays and congestion on this } \\
\text { route. Consequently, everyone ends up with additional travel } \\
\text { time. When part of the travelers take a short detour using a } \\
\text { similar alternative (social route), the remaining travelers on } \\
\text { this route could drive on faster. As a result, we expect to } \\
\text { reduce congestion and improve throughput significantly. You } \\
\text { can contribute by complying with our advice:" }\end{array}$} \\
\hline & & $\begin{array}{c}\text { Route } 1 \\
\text { (usual route) }\end{array}$ & $\begin{array}{c}\text { Route } 2 \\
\text { (social route) }\end{array}$ \\
\hline & $\begin{array}{l}\text { Estimated travel } \\
\text { time }\end{array}$ & 35 minutes** & 39 minutes** \\
\hline
\end{tabular}

"If you drive to work today, we advise you to take route 2. This is the social alternative."

*This number is fixed throughout the experiment.

**Provided travel times are tailored to the participant's choice context and are obtained from Google Maps.

increase safety, reduce emissions-1 level in RP: alleviate congestion) and the travel time sacrifice that was needed in order to comply with the information (continuous). Moreover, we included three two-level attributes related to personality traits (i.e., Social Value Orientation (individualist versus cooperator), Maximizing Tendency (maximizer versus satisficer), Decisional Involvement (habit executioner versus non-habit executioner)), and three attributes related to socio-demographics (i.e., Age $\leq 34$ year, 35-54 year, $\geq 55$ year), Education (professional education versus lower or vocational education) and Gender (male versus female). Note that these are all dummy coded, except for the continuous travel time sacrifice. As not all strategies included information on travel times-in such cases, no 
explicit sacrifice was provided - travel time sacrifice was interacted with a dummy for the presence of travel time information.

The utility function of compliance for the SP-model and the RP-model (note that the utility of the non-compliance option is fixed at zero for normalization purposes):

$$
U_{n t}=A S C+\sum_{m} \beta_{m} x_{m}+v_{n}+\varepsilon_{n t}
$$

In which $U_{n t}$ denotes the total utility associated with compliance by individual $n$ in context $t$. $\beta_{m}$ denotes the parameter to be estimated that is associated with the $m^{\text {th }}$ attribute $x_{m}$. ASC denotes an intrinsic willingness to comply with the advice. Finally, $v_{n}$ and $\varepsilon_{n t}$ are random errors. The former is Normally distributed with a mean of zero and an estimated standard deviation. This error only varies across individuals; it is constant within individuals and across tasks, reflecting a stable inclination of the individual (not) to comply with the information. The latter error is distributed i.i.d. Extreme Value type 1 across both individuals and choice tasks, reflecting additional variation in unobserved utility ('white noise').

Note that the societal goal attribute is not included in the RP-utility function, because only one goal was applied in the RP-experiment.

The applied utility function of compliance for the joint SP/RP-model:

$$
U_{n t}=e^{(\mu \times S P)} \times\left(\mathrm{ASC}+\sum_{m} \beta_{m} x_{m}+v_{n}+\varepsilon_{n t}\right)
$$

In which $\mu$ represents the scale factor that is applied to the SP-dataset in order to obtain the same variance in both datasets. SP indicates to which dataset the observation belongs (i.e., it equals 1 for SP and 0 for RP). Note that $\mu$ equals zero when there is no difference in variance of unobserved utility between the two datasets. The models are estimated using the Biogeme software package (Bierlaire 2003) with the 'donlp2'-algorithm (Spellucci 1993) using at least 1000 Halton draws. Experiments with less draws indicated that 1000 draws were sufficient to obtain stable parameter estimates.

\section{Results}

\section{Descriptive characteristics of samples}

Table 3 describes the samples from both the stated choice and revealed choice experiment and provides information on segmentation of measured personality traits. That is, each personality trait is described by its extremes, resulting in two categories per trait. As the social value orientation measure specifies three categories of which competitors are rarely present in a route choice context, this category is combined with individualists; i.e., they both aim to enhance outcomes for themselves (either absolute or relative). This two-category typology is used by other studies as well (e.g. Van Lange et al. 2011).

There is no evidence that samples are different regarding gender $\left(\chi^{2}=0.0, D F=1, p=.978\right)$, social value orientation $\left(\chi^{2}=2.4, D F=2, p=.295\right)$, decision-making strategy $\left(\chi^{2}=1.4, D F=1, p=.243\right)$ or decisional involvement $\left(\chi^{2}=0.1, D F=1, p=.756\right)$. However, participants in the RP-experiment seem slightly older $\left(\chi^{2}=4.9, D F=2, p=.088\right)$ and higher educated $\left(\chi^{2}=7.8, D F=2, p=.020\right)$ compared to respondents in the SP-experiment. 
Table 3 Descriptive characteristics of samples

\begin{tabular}{|c|c|c|c|}
\hline & $\begin{array}{l}\text { Stated choice } \\
(\mathrm{N}=211)[\%]\end{array}$ & $\begin{array}{l}\text { Revealed choice } \\
(\mathrm{N}=28)[\%]\end{array}$ & \\
\hline \multicolumn{4}{|l|}{ Assigned to information strategy } \\
\hline 1: Recommendation & 25 & \multicolumn{2}{|l|}{50} \\
\hline 2: Nudge & 25 & \multicolumn{2}{|l|}{$\mathrm{n} / \mathrm{a}$} \\
\hline 3: Social Reinforcement & 24 & \multicolumn{2}{|l|}{$\mathrm{n} / \mathrm{a}$} \\
\hline 4: Education & 26 & \multicolumn{2}{|l|}{50} \\
\hline \multicolumn{4}{|l|}{ Gender } \\
\hline Female & 43 & \multicolumn{2}{|l|}{43} \\
\hline Male & 57 & \multicolumn{2}{|l|}{57} \\
\hline \multicolumn{4}{|l|}{ Age } \\
\hline $16-34$ & 50 & \multicolumn{2}{|l|}{32} \\
\hline $35-54$ & 39 & \multicolumn{2}{|l|}{61} \\
\hline$>55$ & 11 & \multicolumn{2}{|l|}{7} \\
\hline \multicolumn{4}{|l|}{ Education } \\
\hline Lower education & 1 & \multicolumn{2}{|l|}{0} \\
\hline $\begin{array}{l}\text { Secondary school or vocational } \\
\text { education }\end{array}$ & 27 & \multicolumn{2}{|l|}{4} \\
\hline Professional education & 72 & \multicolumn{2}{|l|}{96} \\
\hline \multicolumn{4}{|l|}{ Staff category } \\
\hline University: academic & $\mathrm{n} / \mathrm{a}$ & \multicolumn{2}{|l|}{39} \\
\hline University: supportive & $\mathrm{n} / \mathrm{a}$ & \multicolumn{2}{|l|}{43} \\
\hline Company employee & $\mathrm{n} / \mathrm{a}$ & \multicolumn{2}{|l|}{14} \\
\hline No answer & $\mathrm{n} / \mathrm{a}$ & \multicolumn{2}{|l|}{4} \\
\hline Social value orientation & \multicolumn{2}{|c|}{$\begin{array}{l}\text { based on SVO-slider measure by } \\
\text { Murphy et al. (2011) }\end{array}$} & Segmentation: \\
\hline Individualist & 36 & 21 & Non-cooperator \\
\hline Competitor & 1 & 0 & Non-cooperator \\
\hline Cooperator & 63 & 79 & Cooperator \\
\hline Decision-making strategy & \multicolumn{2}{|c|}{$\begin{array}{l}\text { Based on context-free maximizing } \\
\text { tendency scale by Lai (2010) }\end{array}$} & $\begin{array}{l}\text { Segmentation: Average score } \\
\text { on statements... (1-5) }\end{array}$ \\
\hline Maximizer & 76 & 86 & $>3$ \\
\hline Satisficer & 24 & 14 & $\leq 3$ \\
\hline Decisional involvement & \multicolumn{2}{|c|}{$\begin{array}{l}\text { Based on decision involvement scale } \\
\text { by Verplanken et al. (1994) }\end{array}$} & $\begin{array}{l}\text { Segmentation: Average score } \\
\text { on statements... (1-5) }\end{array}$ \\
\hline Habit executioner & 46 & 43 & $<3$ \\
\hline Non-habit executioner & 54 & 57 & $\geq 3$ \\
\hline
\end{tabular}

\section{Compliance rates}

Compliance rates for SP, SI and RP-samples are provided and compared (see Table 4). To enable comparison, the SP-dataset is reduced to only those observations that are similar to the RP-observations; i.e., only observations that contain a 'recommendation'-strategy or 'education'-strategy and involve the congestion alleviation goal are included. 
Table 4 Compliance rates

Usual route chosen Social route chosen Some other route Total [\#]

chosen

\begin{tabular}{|c|c|c|c|c|}
\hline \multicolumn{5}{|l|}{ SP (reduced dataset) } \\
\hline Advice 'Social route' & Non-compliance & Compliance & & \\
\hline Total & $43 \%(70)$ & $57 \%(93)$ & & 163 \\
\hline Overall (full dataset) & $54 \%(601)$ & $46 \%(506)$ & & 1107 \\
\hline \multicolumn{5}{|l|}{ SI } \\
\hline Advice 'Social route' & Non-compliance & Compliance & & \\
\hline Total & $59 \%(13)$ & $41 \%(9)$ & & 22 \\
\hline \multicolumn{5}{|l|}{$\mathrm{RP}$} \\
\hline Advice 'Social route' & Non-compliance & Compliance & Non-compliance & \\
\hline Total & $59 \%(68)$ & $31 \%(36)$ & $10 \%(12)$ & 116 \\
\hline Advice 'Usual route' & Compliance & Non-compliance & Non-compliance & \\
\hline Total & $88 \%(135)$ & $3 \%(5)$ & $8 \%(13)$ & 153 \\
\hline
\end{tabular}

For the RP-experiment, we observe higher compliance rates when the usual route is advised (88\%) compared to when the social detour was advised (31\%); this is as expected. When we compare compliance rates for the social detour for SP and RP, we observe significant differences; compliance in RP (31\%) is significantly lower than compliance in the reduced $\mathrm{SP}(57 \%)\left(\chi^{2}=12.8, D F=1, p=.000\right)$. Nonetheless, compliance rates for taking the detour are similar between SI $(41 \%)$ and RP $(31 \%)\left(\chi^{2}=0.313, D F=1, p=.576\right)$. This suggests a correspondence between what individuals say they would do and what individuals actually do in the context of the field experiment, although this could also be the result of the small sample sizes of the SI and RP datasets.

Note that Djavadian et al. (2014) obtained slightly lower compliance rates (21-28\%) in their laboratory study using strategies based on information and incentives.

\section{Stated intention (SI) versus actual behavior (RP)}

Figure 1 shows to what extent participants behaved in line with their intention during the field-experiment; note that, since SI entails one choice, while RP contains multiple choices, these cannot be compared one to one. $41 \%$ stated to choose the social route. Of these, $89 \%$ actually chose the social route at least once when they faced this situation in reality; $56 \%$ did this even 3 times or more. On the other hand, 59\% stated to stick to their usual route. $38 \%$ of them did indeed not choose the social route alternative in real-life, whereas $46 \%$ chose the social route only once. Overall, participants who intended to take the social route, did this in $56 \%$ of the cases, while others chose the social route in only $17 \%$ of the cases. These findings indicate that there exists a relation between intention and compliance frequency.

\section{Modeling results}

Table 5 shows the estimation results for the SP-model, RP-model and joint SP/RP-model in order to identify explanatory factors for compliance. The SP-model suggests that travelers 




Fig. 1 Stated intention versus actual behavior

have an intrinsic preference for either compliance or non-compliance, which strongly varies among respondents (see the estimate for sigma of $v_{n}$ ). Information strategies based on nudging, social reinforcement and education significantly and positively contribute to information compliance compared to a 'recommend'-strategy. Apparently, travelers need moderate to high information content in order to choose the social route. Moreover, travelers are found to be more likely to comply with the information when information messages pursue the goal of alleviating congestion compared to the goals of increasing safety or reducing emissions. This might be explained by the fact that congestion and travel time are-in the traveler's perception-directly related and therefore alleviating congestion could be perceived as a more meaningful and achievable goal by travelers. Furthermore, the higher the travel time sacrifice, the lower the likelihood of information compliance. This is in line with intuition and findings reported in literature (e.g. Fehr and Fishbacher 2003). Finally, travellers are most likely to comply with the received advice when they are cooperatively oriented and when they make their route choices in a deliberate manner (i.e., non-habitual). Again, this is in line with expectations; cooperators are willing to contribute, while habits are hard to break. Note that the decision-making strategy (i.e., maximizer versus satisficer) was excluded from the final model as it seems to have no significant effect on information compliance. This might be explained by the fact that the maximizing tendency is a quite general personality trait; a person could be in general a maximizer, but when it comes to his route choice specifically, he might be a satisficer. Moreover, one could argue that the combination of maximizing tendency with decision involvement or social value orientation might result in opposite behavior. That is, a cooperative maximizer is presumed to maximize collective outcome and is therefore likely to comply, whereas an individualistic maximizer is presumed to maximize his own outcome and is therefore not likely to comply. Similarly, a habitual satisficer is presumed to stick to his habitual route and therefore not likely to comply, whereas a non-habitual satisficer is presumed to be more willing to switch routes and therefore is more likely to comply. Finally, older travelers seem to be more willing to comply compared to younger travelers, while education and gender do not seem to have any significant effect on information compliance (these were therefore excluded from the final model).

The RP-model suggests information compliance is explained by individuals' intrinsic inclination to (not) comply, which shows strong variation among participants. Other aspects do not seem to significantly influence travelers' compliance; no difference between the 'recommend'-strategy and the 'education'-strategy can be observed and the size of the travel time sacrifice and personality traits do not show any effect. The obtained model 


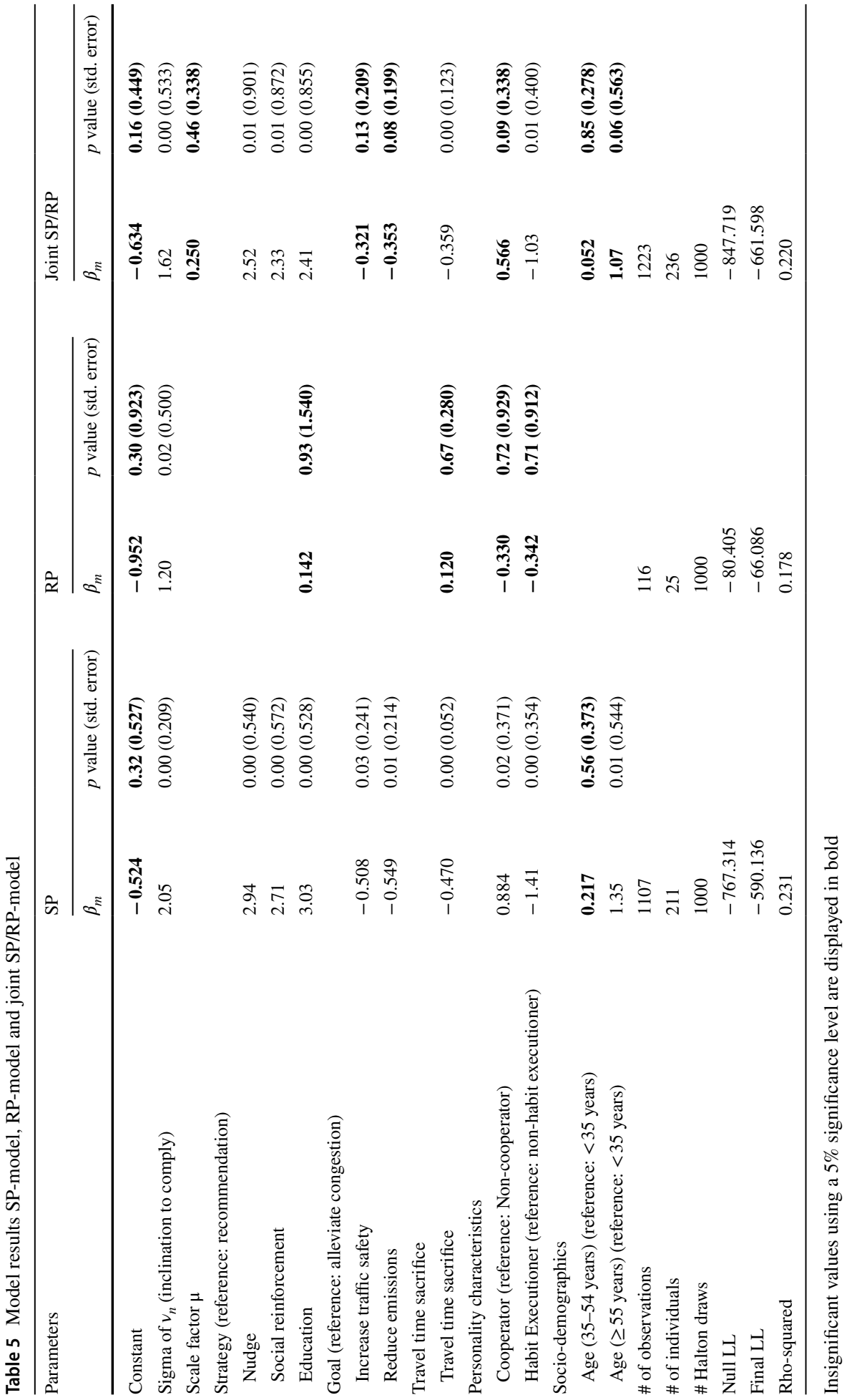


fit is not significantly better than that of a model containing only individuals' intrinsic inclination (likelihood ratio test: $\chi^{2}(4)=1.228, p>.100$ ). Note that the 'age' attribute is not included in the model due to insufficient variability in the obtained data. We refrain from drawing too strong conclusions regarding the difference between responses in the two experiments; due to the small sample size of the RP-experiment, the RP-parameters have such large standard errors that differences between parameters (across experiments) cannot be established statistically.

The joint SP/RP-model shows results similar to the abovementioned findings. Note that the scale factor is not significantly different from zero; this suggests that the variance of unobserved utility or random noise within both the SP-dataset and RP-dataset are similar. $\beta$-estimates are lower than the $\beta$-estimates of the SP-model, while they are higher than the $\beta$-estimates of the RP-model; this is as expected. Moreover, attributes related to the societal goal, social value orientation (i.e., cooperator vs non-cooperator) and age become insignificant.

\section{Analysis of motivations}

Using experience-based sampling, we explore reasons for (non-)compliance with provided route advice. A total of 21 participants, in 153 cases, provided a motivation for (not) following the received advice or, in case of following the advice to use their usual route, whether or not the advice played a role in the decision. Participants could select an answer from a pre-determined list-pre-determined answers were tailored to the experienced situation based on the advice (social route vs usual route) and revealed behavior (follow advice versus not follow advice) — or select 'other' and provide their own answer (note that this option was not often chosen). Each set of pre-determined answers was designed in such a way to be as complete as possible and none of the pre-determined answers overlap. Moreover, each pre-determined answer was formulated quite detailed and specific in order to avoid confusion and misinterpretation. Although multiple answers might be valid in a certain case, participants could only provide one answer; i.e., their most important motivation. Results are shown in Fig. 2.

When the usual route was advised, travelers to an equal degree ignored the advice or felt strengthened in their choice. The main stated reason for not following this advice related to avoiding heavy traffic on that route. These findings indicate that participants did not always fully trust the advice provided by the information system. When the social route was advised, travelers mainly followed this advice because they (stated that they) wanted to contribute to improved network conditions. However, various motivations are provided for not following social route advice; none of them is clearly standing out. First, note that only 3 out of 13 travelers mentioned a too large travel time sacrifice, while the same number of travelers dislikes the social route based on other aspects than travel time. This suggests that travel time sacrifice is not that important in motivating travelers to take the social route as one might expect, at least within the bounds in our experiment (sacrifices: 2-7 min). Moreover, people do not seem to divert to the social route when there is no heavy traffic on their usual route or if they believe the social route will be congested. This supports the earlier mentioned trust issue and indicates that people need to perceive that their effort of switching routes will contribute. This is emphasized by the number of travelers stating that they do not think their choice would influence traffic conditions. Finally, none of the travelers indicated that they did not want to contribute to improved road network conditions. 


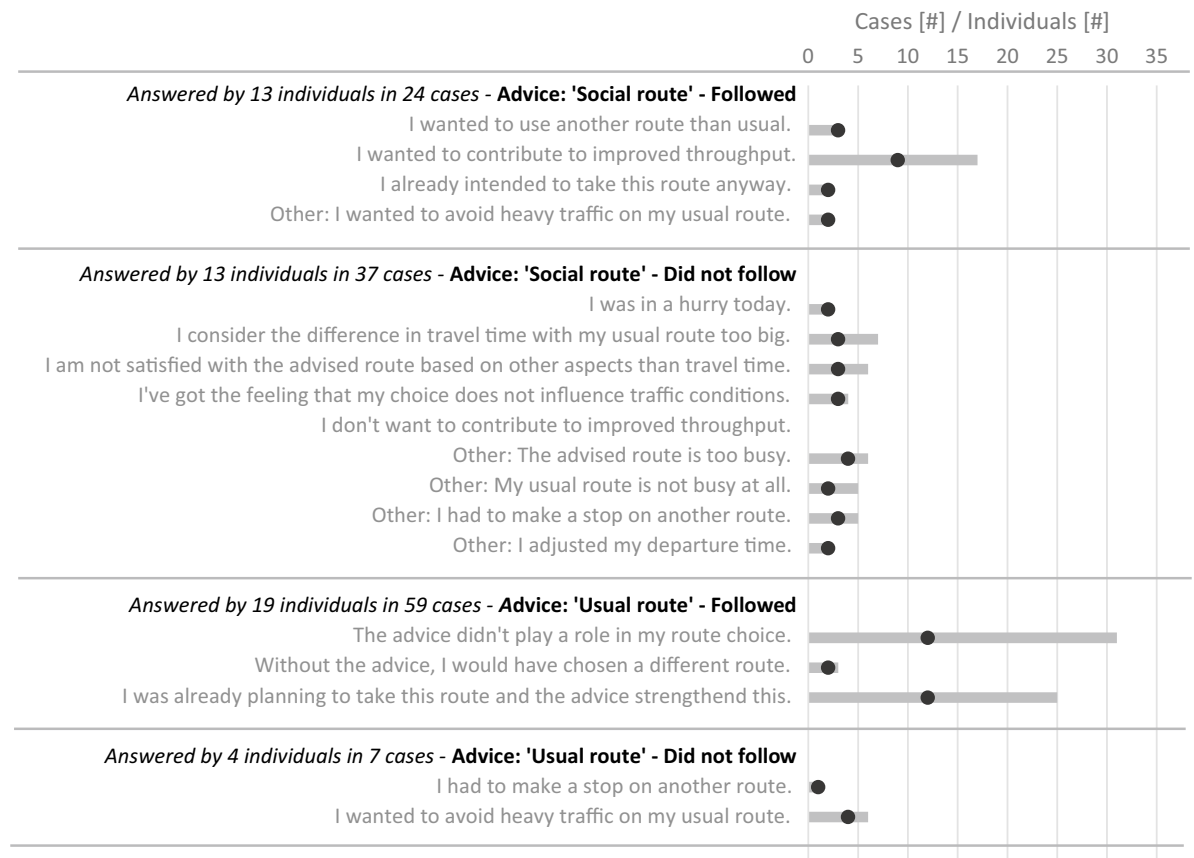

cases individuals

Fig. 2 Analysis of motivations-frequency of answers provided for cases and for individuals

\section{Discussion}

Studies on the topic of compliance behavior in response to social routing advice are scarce. This makes it difficult to draw comparisons between our findings and findings from existing studies. Hence, we include studies on other topics that use similar principles or research methods.

Observed compliance rates in response to social routing advice are similar to compliance rates found in the laboratory study by Djavadian et al. (2014), while they provided incentives (i.e., points) in addition to social routing advice as well. This suggests that incentives might not be that beneficial in stimulating social choice behavior. This is in line with findings by Heyman and Ariely (2004), who found that people are sometimes willing to spend more effort when receiving no payment compared to when receiving a low payment.

Results from the revealed choice experiment suggest that in daily-life people comply less with the advice than would be expected based on stated choice. Hence, our findings between SP and RP appear to be to some extent inconsistent. Note that such inconsistencies between lab- and field experiments have been reported in other studies as well, especially when social preferences are involved (see Levitt and List (2007) for an overview). Nonetheless, compliance rates from stated intentions and revealed choices do bare similarity, and a relation between intention and compliance frequency does appear to exist. Similar results have been obtained by studies that do not involve social choice behavior, such as investigating ridership of new transit services (e.g., Chatterjee et al. 1983) and Couture 
and Dooley (as cited in Chatterjee et al. 1983). A reason for this combination of empirical findings might be that context-related aspects, such as familiarity with routes or trust in the information system, are present in both SI and RP, while absent in SP. This is underpinned by findings from the analysis of motivations in the RP experiment; perceived traffic conditions are the main reason for non-compliance. Abovementioned emphasizes the importance of the application of a field experiment and the usefulness of motivations provided by experience-based sampling.

Sample size remains a major challenge in revealed choice experiments as these are often quite labor-intensive. In our case, the tailored information messages had to be send manually for each participant each day. Our experiment entailed 28 participants, which is comparable to other studies based on revealed route choices; the experiment by Djavadian et al. (2014) has a sample size of 25, the experiment by Tawfik and Rakha (2012) has a sample size of 20, while the experiment by Shiftan, Bekhor, and Albert (2011) has a sample size of only 14. A future solution to this challenge might be found in the set-up of a large-scale living lab integrating research in real-life communities and settings, and the use of a smartphone application that automatically creates tailored messages based on some algorithm.

\section{Conclusion}

This paper contributes to literature on social routing by empirically studying determinants of travelers' compliance with system-optimal travel information and social routing advice. To that end, four distinct information strategies were developed and tested by conducting both a stated choice experiment and a revealed choice experiment in combination with experience-based sampling. We use different societal goals underlying the information and focus on various latent personality characteristics.

Based on the stated choice experiment, we find that travelers sometimes agree to choose the social route over their usual route when they are being advised or asked to do so. A large variation was found in terms of travelers' intrinsic inclination to comply with social routing information. Overall, it seems that travelers' compliance with received information significantly depends on the framing of the information message, its societal goal and the size of the travel time sacrifice. More specifically, we find that travelers are most likely to choose the social alternative when small travel time sacrifices are involved, when information messages are aiming at alleviating congestion, and when these messages are framed according to the 'Nudge'-strategy, 'Social Reinforcement'-strategy or 'Education'-strategy. Moreover, travelers are most likely to comply with the received advice when they are cooperatively oriented and when they make their choices in a non-habitual manner. Results from the revealed choice experiment suggest that in daily-life people comply less with the advice than would be expected based on stated choice. The main motivation for revealed compliance seems to be an intrinsic motivation to contribute to improved throughput and, as such, the applied social information strategies seem to have their intended effect. Finally, analysis of motivations reveals that travel time sacrifice is not that important as expected, while perceived traffic conditions seem to be key. More specifically, compliance rates were low when (perceived) traffic conditions on route alternatives give the impression that there is no need to take a detour (i.e., both alternatives are believed to be busy or both alternatives are believed to be not busy at all).

Whether or not our findings are general, or are partly explained by particularities of our data collection efforts, is an important topic for further research. For example, the small 
sample size might obscure significant findings, while the differences in age and education between both samples might influence observed compliance tendency. Finally, traffic itself did not change according to the choice behavior of the participants. Hence, there was no reward for complying other than experiencing less congestion on the detour route compared to the shortest route. As travel time sacrifices were small, one might argue whether compliance could be attributed to the 'warm glow'-effect (Andreoni 1990) of doing good when the costs for doing so are rather low.

The findings reported in this paper result from a unique combination of a stated choice experiment and a revealed choice experiment that included the collection of motivations using experience-based sampling. Insights from both methods complement each other and provide a more rich understanding of compliance behavior in response to social routing advice. Future research could implement the principles of social routing in a large-scale living lab integrating research in real-life communities and settings in which participants are not aware of taking part in an experiment. Additionally, the use of real-time advice accompanied by navigation instructions might result in higher compliance rates, especially among travelers who are unfamiliar with the surrounding road network. Moreover, dynamics in compliance behavior over a longer time span would provide valuable insights on the long-term effects. Finally, future research should translate the observed (daily-life) compliance rates to the network level in order to indicate to what extent network efficiency could be improved. Overall, with this work we can identify the potential of applying travel information as a travel demand management measure in order to improve network efficiency.

Acknowledgement This work is part of the research programme TRAIL Graduate School, which is financed by the Netherlands Organisation for Scientific Research (NWO). The authors would like to acknowledge the (technical) support of Mobidot who offered their smartphone application for data collection. Caspar Chorus would like to acknowledge funding from the European Research Council: Consolidator Grant BEHAVE, grant number 724431. Finally, the authors would like to thank the anonymous reviewers of this paper for their efforts and valuable comments.

Authors' Contribution ME: Experimental Design, Data Collection and Analyses, Result interpretation, Manuscript Writing and Editing. TT: Experimental Design, Feedback on Analysis, Result Interpretation, Manuscript Editing. EB: Experimental Design, Feedback on Analysis, Result Interpretation, Manuscript Editing. CC: Experimental Design, Feedback on Analysis, Result Interpretation, Manuscript Editing.

\section{Compliance with ethical standards}

Conflict of interest On behalf of all authors, the corresponding author states that there is no conflict of interest.

Open Access This article is distributed under the terms of the Creative Commons Attribution 4.0 International License (http://creativecommons.org/licenses/by/4.0/), which permits unrestricted use, distribution, and reproduction in any medium, provided you give appropriate credit to the original author(s) and the source, provide a link to the Creative Commons license, and indicate if changes were made.

\section{References}

Ajzen, I.: The theory of planned behavior. Organ. Behav. Hum. Decis. Process. 50(2), 197-211 (1991). https ://doi.org/10.1016/0749-5978(91)90020-T

Anas, A., Lindsey, R.: Reducing urban road transportation externalities: road pricing in theory and in practice. Rev. Environ. Econ. Policy 5(1), 66-88 (2011). https://doi.org/10.1093/reep/req019

Andreoni, J.: Impure altruism and donations to public goods: a theory of warm-glow giving. Econ. J. 100(401), 464-477 (1990). https://doi.org/10.2307/2234133 
Araghi, Y., Kroesen, M., Molin, E.J.E., Van Wee, B.: Do social norms regarding carbon offsetting affect individual preferences towards this policy? Results from a stated choice experiment. Transp. Res. Part D Transp. Environ. 26, 42-46 (2014). https://doi.org/10.1016/j.trd.2013.10.008

Avineri, E. (2009a). Nudging travellers to make better choices. In: Paper presented at the International Choice Modelling Conference, March 30th till April 2nd, 2009, Harrogate, UK. http://www.icmco nference.org.uk/index.php/icmc/icmc2009/paper/viewFile/148/50

Avineri, E.: Social value orientation and the efficiency of traffic networks. In: Kitamura, R., Yoshii, T., Yamamoto, T. (eds.) The expanding sphere of travel behaviour research, pp. 725-743. Emerald, Bingley $(2009 b)$

Ben-Akiva, M., de Palma, A., Kaysi, I.: Dynamic network models and driver information systems. Transp. Res. Part A Gen. 25(5), 251-266 (1991). https://doi.org/10.1016/0191-2607(91)90142-D

Braess, D., Nagurney, A., Wakolbinger, T.: On a paradox of traffic planning. Transp. Sci. 39(4), 446-450 (2005). https://doi.org/10.1287/trsc.1050.0127

Carrion, C. (2013). Travel time perception errors: causes and consequences. (Ph.D.-thesis), University of Minnesota. http://hdl.handle.net/11299/155609

Chatterjee, A., Wegmann, F.J., McAdams, M.A.: Non-commitment bias in public opinion on transit usage. Transportation 11(4), 347-360 (1983). https://doi.org/10.1007/BF00150723

Ciscal-Terry, W., Dell'Amico, M.D., Hadjidimitriou, N.S., Lori, M.: An analysis of drivers route choice behaviour using GPS data and optimal alternatives. J. Transp. Geogr. 51(2016), 119-129 (2016). https ://doi.org/10.1016/j.jtrangeo.2015.12.003

Djavadian, S., Hoogendoorn, R.G., van Arem, B., Chow, J.Y.J.: Empirical evaluation of drivers' route choice behavioral responses to social navigation. Transp. Res. Rec. J. Transp. Res. Board 2423, 52-60 (2014). https://doi.org/10.3141/2423-07

Ettema, D., Knockaert, J., Verhoef, E.T.: Using incentives as traffic management tool: empirical results of the 'peak avoidance' experiment. Transp. Lett. 2(1), 39-51 (2010). https://doi.org/10.3328/ TL.2010.02.01.39-51

Fehr, E., Fishbacher, U.: The nature of human altruism. Nature 425(6960), 785-791 (2003). https://doi. org/10.1038/nature02043

Georgescu-Roegen, N.: Choice, expectations and measurability. Q. J. Econ. 68(4), 503-534 (1954)

Hektner, J., Schmidt, J., Csikszentmihalyi, M.: Experience Sampling Method-Measuring the Quality of Everyday Life. Sage Publications, Thousand Oaks (2007)

Heyman, J., Ariely, D.: Effort for payment. A tale of two markets. Psychol. Sci. 15(11), 787-793 (2004). https://doi.org/10.1111/j.0956-7976.2004.00757.x

Hoogendoorn-Lanser, S., Schaap, N.T.W., Olde Kalter, M.J.: The Netherlands Mobility Panel: an innovative design approach for web-based longitudinal travel data collection. Transp. Res. Proc. 11(2015), 311-329 (2015). https://doi.org/10.1016/j.trpro.2015.12.027

Jahn, O., Möhring, R.H., Schulz, A.S., Stier-Moses, N.E.: System-optimal routing of traffic flows with user constraints in networks with congestion. Oper. Res. 43(4), 600-616 (2005). https://doi.org/10.1287/ opre. 1040.0197

Jakobssen, C. (2003). Household planning of car use: implementation of prospective car logs. In: Paper presented at the 10th International Conference on Travel Behaviour Research, Lucerne, Switzerland, August 10-15, 2003

Johnson, E.J., Payne, J.W.: Effort and accuracy in choice. Manage. Sci. 31(4), 395-414 (1985). https://doi. org/10.1287/mnsc.31.4.395

Kahneman, D., Tversky, A.: Prospect theory: an analysis of decision under risk. Econom. J. Econom. Soc. 47(2), 263-292 (1979). https://doi.org/10.2307/1914185

Klein, I., Levy, N., Ben-Elia, E.: An agent-based model of the emergence of cooperation and a fair and stable system optimum using ATIS on a simple road network. Transp. Res. Part C 2018(86), 183-201 (2018). https://doi.org/10.1016/j.trc.2017.11.007

Knight, G.P., Dubro, A.F.: An individualized regression and clustering assessment of the social values of adults and children. J. Res. Pers. 18(3), 372-382 (1984). https://doi.org/10.1016/0092-6566(84)90021 $-7$

Kroes, E.P., Sheldon, R.J. (1988) Stated preference method: an introduction. J. Transport Econ. Policy, 22(1), 11-25. http://www.jstor.org/stable/20052832

Lai, L.: Maximizing without difficulty: a modified maximizing scale and its correlates. Judgm. Decis. Mak. 5(3), 164-175 (2010)

Levitt, S. D., \& List, J. A. (2007). What do laboratory experiments measuring social preferences reveal about the real world? Journal of economic perspectives, 21(2), 153-174. http://www.jstor.org/stabl e/30033722 
Levy, N., Klein, I., Ben-Elia, E.: Emergence of cooperation and a fair system optimum in road networks: a game-theoretic and agent-based modelling approach. Res. Transp. Econ. (2017). https:// doi.org/10.1016/j.retrec.2017.09.010

Liebrand, W.B.G.: The effect of social motives, communication and group size on behaviour in an N-person multi-stage mixed-motive game. Eur. J. Soc. Psychol. 14(3), 239-264 (1984). https://doi. org/10.1002/ejsp.2420140302

Murphy, R.O., Ackermann, K.A., Handgraaf, M.J.J.: Measuring Social Value Orientation. Judgm. Decis. Making 6(8), 771-781 (2011). https://doi.org/10.2139/ssrn.1804189

Nilsson, M., Küller, R.: Travel behaviour and environmental concern. Transp. Res. Part D Transport Environ. 5(3), 211-234 (2000). https://doi.org/10.1016/S1361-9209(99)00034-6

Ostrom, E., Walker, J.L.: Trust and reciprocity: interdisciplinary lessons from experimental research. Russell Sage Foundation, New York (2003)

Pichert, D., Katsikopolous, K.V.: Green defaults: information presentation and pro-environmental behaviour. J. Environ. Psychology 28, 63-73 (2007). https://doi.org/10.1016/j.jenvp.2007.09.004

Platow, M.J.: Observing social value orientations: a social interdependence approach. N. Z. J. Psychol. 22(2), 101-109 (1993)

Poteete, A.R., Janssen, M.A., Ostrom, E.: Working Together: Collective Action, the Commons, and Multiple Methods in Practice. Princeton University Press, Oxfordshire (2010)

Pruitt, D.G., Kimmel, M.J.: Twenty years of experimental gaming: critique, synthesis, and suggestions for the future. Annu. Rev. Psychol. 28, 363-392 (1977). https://doi.org/10.1146/annur ev.ps.28.020177.002051

Roughgarden, T.: Selfish Routing and the Price of Anarchy. MIT Press, Cambridge (2006)

Schwartz, S.H.: Normative influences on altruism. In: Berkowitz, L. (ed.) Advances in Experimental Social Psychology, vol. 10, pp. 221-279. Academic Press, New York (1977)

Sen, A.K.: Rational Fools: A critique of the behavioural foundations of economic theory. Philos. Public Aff. 6(4), 317-344. (1977) http://www.jstor.org/stable/2264946

Shiftan, Y., Bekhor, S., Albert, G.: Route choice behaviour with pre-trip travel time information. Intell. Transp. Syst. 5(3), 183-189 (2011). https://doi.org/10.1049/iet-its.2010.0062

Simon, H.A.: A behavioral model of rational choice. Q. J. Econ. 69(1), 99-118 (1955). https://doi. org/10.2307/1884852

SMART in Twente. (2016). Smartphone application 'SMART-Mobiliteit' (Version 2.2). www.smart intwente.nl

Stanovich, K.E., West, R.F.: Individual differences in reasoning: implications for the rationality debate? Behav. Brain Sci. 23(5), 645-665 (2000). https://doi.org/10.1017/S0140525X00003435

Sunstein, C.., \& Thaler, R.H.: Libertarian paternalism is not an oxymoron. Univ. Chicago Law Rev. 70(4), 1159-1202. doi:http://www.jstor.org/stable/1600573 (2003)

Tawfik, A.M., Rakha, H.A.: Network route-choice evolution in a real-world experiment: a necessary shift from network to driver oriented modeling. Transp. Res. Rec. J. Transp. Res. Board 2322, 70-81 (2012). https://doi.org/10.3141/2322-08

Te Brömmelstroet, M.: Sometimes you want people to make the right choices for the right reasons: potential perversity and jeopardy of behavioural change compaigns in the mobility domain. J. Transp. Geogr. 39(2014), 141-144 (2014). https://doi.org/10.1016/j.jtrangeo.2014.07.001

Tversky, A., Kahneman, D.: Loss aversion in riskless choice: a reference-dependent model. Q. J. Econ. 106(4), 1039-1061 (1991). https://doi.org/10.2307/2937956

Van den Bosch, A., Van Arem, B., Mahmod, M., \& Misener, J. (2011). Reducing time delays on congested road networks using social navigation. In: Paper Presented at the IEEE Forum on Integrated and Sustainable Transportation Systems, Vienna, Austria, June 29

Van Essen, M., Thomas, T., Van Berkum, E., Chorus, C.G.: From user equilibrium to system optimum: a literature review on the role of travel information, bounded rationality and non-selfish behaviour at the network and individual levels. Transp. Rev. A Transnatl. Transdiscipl. J. 36(4), 527-548 (2016). https://doi.org/10.1080/01441647.2015.1125399

Van Lange, P.A.M., Otten, W., De Bruin, E.M.N., Joireman, J.A.: Development of prosocial, individualistic, and competitive orientations: theory and preliminary evidence. J. Pers. Soc. Psychol. 73(4), 733-746 (1997). https://doi.org/10.1037/0022-3514.73.4.733

Van Lange, P.A.M., Schippers, M., Balliet, D.: Who volunteers in psychology experiments? An empirical review of prosocial motivation in volunteering. Pers. Individ. Differ. 51(3), 279-284 (2011). https:// doi.org/10.1016/j.paid.2010.05.038

Van Lange, P.A.M., Van Vugt, M., Meertens, R.M., Ruiter, R.A.C.: A social dilemma analysis of commuting preferences: the roles of social value orientation and trust. J. Appl. Soc. Psychol. 28(9), 796-820 (1998). https://doi.org/10.1111/j.1559-1816.1998.tb01732.x 
Van Vugt, M., Van Lange, P.A.M., Meertens, R.M.: Commuting by car or public transportation? A social dilemma analysis of travel mode judgement. Eur. J. Soc. Psychol. 26(3), 373-395 (1996). https://doi. org/10.1002/(SICI)1099-0992(199605)26:3\%3c373:AID-EJSP760\%3e3.0.CO;2-1

Verhoef, E.T., Nijkamp, P., \& Rietveld, P.: The social feasibility of road pricing: a case study for the Randstad Area. J. Transport Econ. Policy, 31(3), 255-276. http://www.jstor.org/stable/20053739

Verhoef, P.C., Franses, P.H.: Combining revealed and stated preferences to forecast customer behavior: three case studies. Int. J. Market Res. 45(4), 467-474 (2003). https://doi.org/10.1177/147078530304500402

Verplanken, B., Aarts, H., Van Knippenberg, A.: Habit, information acquisition, and the process of making travel mode choices. Eur. J. Soc. Psychol. 27(5), 539-560 (1997). https://doi.org/10.1002/(SICI)10990992(199709/10)27:53.0.CO;2-A

Verplanken, B., Aarts, H., Van Knippenberg, A., Van Knippenberg, C.: Attitude versus general habit: antecedents of travel mode choice. J. Appl. Soc. Psychol. 24(4), 285-300 (1994). https://doi. org/10.1111/j.1559-1816.1994.tb00583.x

Vreeswijk, J., Rakha, H., Van Berkum, E., Van Arem, B.: Analysis of inertial choice behaviour based expected and experienced savings from a real-world route choice experiment. Int. J. Transp. 3(3), 11-28 (2015). https://doi.org/10.14257/ijt.2015.3.3.02

Wardman, M.: A comparison of revealed preference and stated preference models of travel behaviour. J. Transport Econ. Policy, 22(1), 71-91. http://www.jstor.org/stable/20052836 (1988)

Waze. (2018). Free Community-based GPS, Maps \& Traffic Navigation Appl Waze. Retrieved from https:// www.waze.com/en/

Xu, Y., Gonzalez, M.C.: Collective benefits in traffic during mega events via the use of information technologies. J. R. Soc. Interface (2017). https://doi.org/10.1098/rsif.2016.1041

Yamagishi, T.: The provision of a sanctioning system in the United States and Japan. Soc. Psychol. Q. 51(3), 265-271 (1988). https://doi.org/10.2307/2786924

Zajonc, R.B.: Feeling and thinking: preferences need no inferences. Am. Psychol. 35(2), 151-175 (1980). https://doi.org/10.1037/0003-066X.35.2.151

Zhu, S., \& Levinson, D. (2010). Do people use the shortest path? An empirical test of Wardrop's first principle. In: Paper Presented at the 91st TRB Annual Meeting, January 22-26, 2012, Washington, DC, USA

Çolak, S., Lima, A., González, M.C.: Understanding congested travel in urban areas. Nat. Commun. 7, 1-8 (2016). https://doi.org/10.1038/ncomms10793

Mariska van Essen is a $\mathrm{PhD}$ candidate at the University of Twente. She obtained a master degree in civil engineering and management at the same university. Her research focusses on the use of personalized travel information in order to stimulate social route choice behavior and improve road network efficiency.

Tom Thomas is an assistant professor at the University of Twente. He received both a $\mathrm{PhD}$ and master in Astronomy at the University of Leiden. His topics of interest are travel behavior, modeling traffic flows, and developing algorithms for the prediction of travel times.

Eric van Berkum is professor of traffic engineering and management at the Centre for Transport Studies at the University of Twente. He received a PhD in Civil Engineering from Delft University of Technology and a master in Applied Mathematics at the University of Twente. His current research focuses on the optimization of transport networks.

Caspar Chorus is professor of Choice behavior modelling at the Engineering Systems and Services department at Delft University of Technology. He received his PhD (highest distinction) from TU Delft, on his dissertation "Traveler response to information". His current research focuses on developing and testing models of moral decision making for human and artificial agents. 